ALPHA N 29 Diciembre 2009 (217-232)

ISSN 0716-4254

http://alpha.ulagos.cl

\title{
EL SABER DE LOS FANTASMAS: IMAGINARIOS Y FICCIÓN
}

Knowledge from phantoms: fiction and imaginary

\author{
Lucero de Vivanco Roca Rey*
}

\begin{abstract}
Se trata aquí de un conocimiento que no sólo necesita los sentidos sino también los sentimientos, no sólo razón sino pasión. Se trata aquí de saberes... que no se someten al sistema ni se entregan al concepto sino que prefieren el ritmo narrativo de una saga, la rigurosa y amable disciplina de un poema... o la aparente sencillez de un cuento.

Patxi Lanceros
\end{abstract}

Resumen

El presente estudio se enmarca dentro de la teoría literaria y pretende ampliar este campo de discusión trayendo a escena una noción de uso frecuente hoy en día en la filosofía y en las ciencias sociales: lo imaginario. Esta noción se define a partir de las propuestas de Gilbert Durand y Cornelius Castoriadis y se articula con algunos de los problemas más recurrentes en las teorías de la literatura. Se propone, finalmente, un estatuto epistemológico para la ficción.

Palabras clave: Imaginario, ficción, conocimiento, imaginación.

\begin{abstract}
In the field of literary theory, this article articulates two concepts: the imaginary (defined following Gilbert Durand's and Cornelius Castoriadis' theorical proposals) and fiction. This paper discusses how the imaginary perspective confronts recurrent problems in fiction theories, and proposes an epistemological statute for fiction.
\end{abstract}

Key words: Imaginary, fiction, knowledge, imagination.

POR QUÉ LO IMAGINARIO

Fantasmas y saberes son términos que se identifican con dos paradigmas que no suelen asociarse. Los fantasmas son invocados desde la superstición, la magia, la alucinación, el sueño. Los saberes operan sobre el conocimiento, la razón, la objetividad, la especulación. Los textos y los discursos que conducen a unos y a otros se encuentran únicamente en el terreno de la disputa: el texto poético, que nunca termina de adicionar vivencias, cifra su carácter en el símbolo; el texto teórico, que se anuncia 


\section{Lucero de Vivanco Roca Rey}

siempre coetáneo, compendia su sapiencia en el concepto. Parece que la humanidad hubiera recorrido un esforzado camino para sacrificar a unos en pos de la consagración de los otros; que hubiera entendido su "progreso" o su "evolución" como un desprendimiento violento de todo aquello que pudiera hacerle sombra al conocimiento juicioso, a la razón iluminante. Sin embargo, los fantasmas encuentran su propia luz en su etimología ${ }^{1} \mathrm{y}$, en ella, un saber propio. El saber de la phantasia y la phantasmata es el saber de la imaginación y sus gestos: los imaginarios, la poesía, la ficción.

El desafío de articular los imaginarios y la ficción literaria recoge, por un lado, el interés que se ha despertado en torno a los estudios de los imaginarios en los últimos años en el campo de las ciencias humanas y sociales, testimonio del inmenso potencial de rendimiento de esta noción y de la serie conceptual que la acompaña. Pero el uso difundido de esta noción también ha dado pie para su abuso: con frecuencia se reduce su complejidad, cuando no se usa como un mero comodín conceptual. De allí la necesidad de esclarecer y definir este concepto. Por otro lado, también durante los últimos años se ha experimentado una revitalización de las discusiones en torno a la ficción literaria. ¿Qué razones están en la base de este resurgimiento? La posibilidad de que la ficción sea concebida como una instancia privilegiada para la comprensión de la experiencia humana es una de ellas. Lo es, también, la necesidad de ampliar los horizontes de sentido en el mundo actual y de resituarse frente a escenarios en los que se han oscurecido las antiguas fronteras entre la realidad y la ficción. No solo la "cibercultura" sería una evidencia de lo anterior. Desde hace ya varios años, por ejemplo, las literaturas latinoamericanas buscan elaborar los procesos traumáticos y violentos de sus propias experiencias históricas y nadie podría negar hoy en día que los productos literarios que surgen de dichas elaboraciones, aunque tengan un carácter "subjetivo" o "ficcional”, son una herramienta fundamental para construir el conocimiento histórico. La cercanía de la muerte, la crisis y la traición, la persecución y la derrota, la frustración y el miedo, pero también el anhelo, la memoria y la esperanza son los epítetos de los nombres del mundo con los que narramos lo que somos, lo que queremos llegar a ser y lo que nunca quisiéramos repetir de nosotros mismos, como individuos y como sociedades. Por todas estas razones, resulta central comprender la función que cumplen los imaginarios en el mundo contemporáneo, así como también -y de manera particular en la teoría literaria- - volver a revisar el territorio de la

\footnotetext{
${ }^{1}$ Aristóteles señala: "Y como la vista es el sentido por excelencia, la palabra "imaginación” (phantasia) deriva de la palabra "luz" (pháos) puesto que no es posible ver sin luz" (Acerca del alma. Madrid: Gredos, 2003:229).
} 
ficción en contraposición con el de la no-ficción, es decir, con la realidad, la sociedad y la historia.

\section{LO IMAGINARIO: UNA FANTÁSTICA TRASCENDENTAL}

Lo imaginario, fruto de la imaginación creadora ${ }^{2}$ y no de la imaginación reproductora (véase infra) se erige como el dominio simbólico que todo individuo y toda sociedad posee inalienablemente, redefiniéndose de manera continua en los actores de la historia. Lo imaginario funge de sustrato cultural y social y, como tal, se le puede reconocer en todo lo creado e instituido, basculando entre lo sincrónico y lo diacrónico, retroalimentando tanto las representaciones arquetípicas como las acciones concretas. En lo imaginario concurren desde las instituciones sociales y sus leyes hasta los mitos y fantasmas. Nada escapa a lo imaginario: ni el arte, ni la literatura, ni las ideologías, ni las opciones religiosas, ni las interpretaciones históricas, ni las neurosis, ni los sistemas filosóficos o científicos.

Hay dos aspectos tratados por Gilbert Durand que resultan particularmente interesantes para construir el campo teórico que aquí se propone: el contenido semántico de lo imaginario y su función. En cuanto a lo primero, Durand define lo imaginario en relación con el símbolo. En este sentido, establece una escala de gradación en el modo como la conciencia dispone las imágenes para vincularse con el mundo. En un extremo sitúa el signo tal como fue concebido por Saussure, es decir, un signo en el que la relación entre el significado y el significante es adecuada en tanto que el significante consigue remitirse a una realidad que, aunque no esté presente, por lo menos siempre es posible de presentar. En el otro extremo sitúa Durand al símbolo en una relación de inadecuación máxima entre significado y significante, en tanto que el significante del símbolo evoca siempre "algo ausente e imposible de percibir” (2000:13). Consecuencia de esta inadecuación, de esta lejanía con

\footnotetext{
${ }^{2}$ Castoriadis hace una distinción entre imaginación primera e imaginación segunda (149-176) a partir del tratado de Aristóteles Acerca del alma. Según Castoriadis, la filosofía rescató sólo uno de los dos sentidos de la imaginación consignados en ese tratado por Aristóteles, el de la imaginación segunda o imaginación reproductora, e ignoró la otra imaginación (apenas insinuada por Aristóteles) que Castoriadis llama imaginación primera o imaginación creadora. Es la imaginación segunda la que ha sido entendida comúnmente como "imaginación” y, como tal, banalizada por el "verdadero" conocimiento y por la cultura de la razón, por estar ligada al ámbito sensorial y tener únicamente un carácter reproductor. Por el contrario, la imaginación primera tiene un alcance ontológico al permitir no sólo reproducción de realidad y pensamiento, sino al ser condición de posibilidad del pensamiento y de la realidad social. Ligada a lo que Castoriadis llama sociedad instituyente, la imaginación creadora es instauradora: posibilita la actuación autónoma de las sociedades para cuestionar sus paradigmas institucionales y crear nuevos imaginarios sociales dentro del dominio historicosocial.
} 


\section{Lucero de Vivanco Roca Rey}

el mundo sensible, el símbolo conduce ya no a una presentación del significado sino a la representación de un sentido.

Si bien de esta manera de entender el contenido semántico de lo imaginario se podría deducir que éste está cerrado al plano del empirismo, por ningún motivo se debe colegir que está cerrado al plano de la experiencia humana. Por el contrario, lo imaginario pone en el centro el conocimiento de lo humano en toda su complejidad y en toda su diversidad; esto es, incorpora el espacio en el que se escenifica lo oculto, lo frustrante, lo inmanejable, lo inexplicable. El símbolo "hace aparecer un sentido secreto — afirma Durandes la epifanía de un misterio” (2000:15). El hecho de que el símbolo remita a algo ausente e imposible de percibir quiere, también, decir que el mundo se amplía con dichos elementos ausentes o imposibles de percibir. Los límites de la realidad establecida experimentan, así, un retroceso para demarcar un universo vivencial más amplio, que dé cabida a todo el espectro imaginativo, que atraiga hacia sí originales y hasta insospechados planos de la existencia. Con lo imaginario los individuos desbordan la realidad factual e introducen nuevos ámbitos de realidad en interacción con los contextos históricos y culturales, de modo tal que el ser humano da sentido a su praxis y la hace más comprensible.

En relación al segundo aspecto, Durand se ha referido insistentemente a la función eufémica de lo imaginario, la que responde a la necesidad antropológica de equilibrar la situación del ser humano en el mundo con respecto a su finitud temporal y a su angustia escatológica. El eufemismo sobre la finitud del tiempo y la inevitabilidad de la muerte es el sentido supremo de lo imaginario. Según Durand: "Todos aquellos que se inclinaron de una manera antropológica — es decir, a la vez, con humildad científica y amplitud de horizonte poético - sobre el campo de lo imaginario están de acuerdo en reconocer a la imaginación, en todas sus manifestaciones... ese poder realmente metafísico de alzar sus obras contra la podredumbre de la muerte y del destino” (2004:411). No obstante, habría que agregar que si bien el imaginario cumple la función de "eufemizar" la irreversibilidad del tiempo, no es un "mero opio negativo" con el cual disimular las máscaras de la muerte, aclara Durand. Por el contrario, se trata de un "dinamismo prospectivo que, a través de todas las estructuras del proyecto imaginario, procura mejorar la situación del hombre en el mundo" (2000:127). Esto implica eufemizar también las pérdidas y fracturas propias de toda experiencia vital y, sobre todo, trascender la realidad en su facticidad, en sus objetivaciones cotidianas y en sus elementos establecidos, función en la que la ficción suele desarrollar un papel de excelencia. Y la trascendencia se constituye a partir de la facultad creadora y radical de la imaginación, de su soberanía y su autonomía para ensanchar el mundo social y construirlo desde sus elementos fantasmagóricos, desde sus 
sueños, desde sus ficciones literarias y sus significaciones simbólicas e imaginarias. Si figurar la muerte es un modo de dominarla y de cimentar vida a cambio, imaginar el mundo es una manera de trascenderlo e instituirlo. Es a través de lo imaginario que se "desborda en gran manera la simple aventura mortal y prohíbe la alienación del espíritu en una acomodación objetiva” (2004:411).

En un sentido similar y, al mismo tiempo, complementario puede interpretarse la función de lo imaginario social propuesta por Cornelius Castoriadis en Los dominios del hombre. Según Castoriadis, toda sociedad se mantiene cohesionada gracias a la "institución de la sociedad como un todo", lo que hace referencia al conjunto de sus instituciones particulares, sus valores, sus normas, su lenguaje, sus individuos, etc.; en suma, a una "urdimbre inmensamente compleja de significaciones que empapan, orientan y dirigen toda la vida de la sociedad considerada y a los individuos concretos que corporalmente la constituyen” (1998:68). Pero toda sociedad instituida presupone una sociedad instituyente, en la que adquiere forma y función el lenguaje de la imaginación radical. La sociedad instituyente es la que tiene la capacidad de crear en pleno ejercicio de su autonomía, a través de un acto de apertura en el que se pone en tela de juicio su propia ley y se cuestiona el orden establecido. La sociedad instituyente es la que inventa y se inventa, la que cuestiona su ontología y genera nuevas formas de ser sociales, poniendo un sello identitario y haciendo avanzar la historia. En efecto, Castoriadis entiende lo social siempre dentro del campo histórico, estableciendo el dominio históricosocial como el más propio del hombre. Para él, la dimensión histórica es lo que permite y gatilla las alteraciones sociales e identitarias y los cambios del orden o desorden dado. La imaginación creadora y la sociedad instituyente se despliegan, entonces, en la historia; la historia es creación de significaciones imaginarias, es "imaginario social”. Dice Castoriadis: "Llamo imaginarias a estas significaciones porque no corresponden a elementos 'racionales' o 'reales' y no quedan agotadas por referencia a dichos elementos, sino que están dadas por creación” (1998:68). En este sentido, “toda sociedad es una construcción, una constitución, creación de un mundo, de su propio mundo. Su propia identidad no es otra cosa que ese sistema de interpretación, ese mundo que ella crea" (1998:69).

Se podría decir entonces, siguiendo a Durand y Castoriadis, que la imaginación creadora es la facultad antropológica con la cual es posible instalar imaginarios en el mundo y construir mundos a partir de imaginarios. Lo anterior se consigue porque lo imaginario es una categoría que se mantiene al margen de los esquemas de determinación y de los principios tradicionales de la lógica científica - desde donde fue históricamente denostada- configurándose, más bien, en el mínimo común de todo pensamiento y de toda 


\section{Lucero de Vivanco Roca Rey}

representación. Adquiere su grandeza, en este sentido, al ser un fundamento para el encuentro de todos los seres humanos en la aspiración de lo permanente y lo universal. Ya sea de manera individual o colectiva, la revelación semántica que germina en lo imaginario otorga al ser humano la comprensión necesaria para permanecer en el mundo, la fuerza para modificarlo y la creatividad para inventarlo.

\section{IMAGINARIOS Y FICCIÓN: EL CONTRAPUNTO}

¿Cómo argumentar el estudio de los imaginarios en el campo de la ficción literaria? El respaldo más claro viene dado por el lugar generativo que ocupa la imaginación en relación a la ficción. Así lo entiende Antonio Garrido cuando consiente que "el estudio del despliegue imaginario del texto se justifica plenamente en un trabajo sobre la ficción en cuanto que lo ficcional implica como rasgo básico la construcción imaginaria de mundos” (1997:37). Pero, aunque este "rasgo básico" resulte evidente y conocido, el argumento deviene en algo novedoso por la densificación semántica que han adquirido en los últimos años las nociones de imaginación y de imaginario concebidas al interior de las líneas teóricas que encabezan Durand y Castoriadis. En este sentido, la ficción literaria al ser una instancia particularmente pertinente para que se manifieste lo imaginario, corresponde extrapolarle e imprimirle toda la adjetivación y la caracterización atribuidas a éste.

Los problemas alrededor de los cuales se plantea enfocar, aquí, la postura de los imaginarios frente a las teorías de la ficción se ajustan a tres tipos de cuestionamientos. Primero, a un tipo de preguntas que inquieren por la naturaleza ontológica de la ficción en relación a su estatuto cognitivo. En otras palabras, por la definición de ficción en su estrecho vínculo con el orden de la "verdad" y el conocimiento. Segundo, a preguntas que apuntan a delimitar el campo semántico de la ficción, por lo que indagan fundamentalmente en los problemas de la referencialidad y la representación. Por último, a preguntas que procuran establecer la función de la ficción en el plano cultural, escudriñando las convenciones que cada sociedad pacta en un determinado momento histórico (Pavel, 1995). Estos problemas no pueden formularse ni discutirse de manera desarticulada. Al mirar la ficción desde el campo teórico de lo imaginario y de su enfoque principalmente semántico, surge una interrogación sólo en apariencia ingenua: ¿De qué habla la ficción y qué valor se le otorga a aquello de lo que habla? La respuesta dada desde lo imaginario enfatiza la indisociabilidad de las posibilidades que la ficción ofrece y adopta para expresar y construir el mundo, es decir, para relacionarse con la realidad, de las que ofrece y adopta para conocerlo y hacerlo comprensivo, es decir, para desplegar el quehacer cognitivo de la literatura en particular y 
del arte, en general. Cada uno de los niveles explicitados incluye a los otros dos: entender la ficción literaria como uno de los resultados de la imaginación creadora involucra necesariamente pensar en su ontología cognitiva, en sus relaciones con lo existente y en un campo de sentido para lo humano.

Esta perspectiva integradora de los distintos niveles involucrados en la ficción literaria puede visualizarse mejor si se considera que la integración también ha sido expuesta en función de sus "efectos negativos". Cuando Platón, en La República, se refería a la poesía mimética como "fábulas ficticias", "mentiras" o "falsedades" y expulsaba a los poetas de la ciudad ideal, le estaba atribuyendo a la ficción características nocivas en los tres niveles arriba mencionados. El arte mimético, según Platón, refleja las cosas alejadas en tercer grado de las ideas esenciales y verdaderas, adjudicando a la divinidad y al artesano los dos primeros grados respectivamente. En este sentido, su facultad referencial apunta únicamente a sombras, apariencias, simulacros, copias de copias, lo que menoscaba la potencia cognoscitiva de la mímesis. Más aún, si Platón confiere a la mímesis alguna función en la experiencia humana cotidiana, ésta se acuña sobre el temor a que la ficción produzca un "efecto de arrastre" (Schaeffer, 2002:19), un contagio de conductas reprensibles y una injerencia perniciosa en los comportamientos de la vida real. La segregación platónica aplicada a la mímesis se convirtió en la matriz de un discurso antimimético argüido a lo largo de la historia. Según Jean-Marie Schaeffer, quien da cuenta de este rechazo en los primeros capítulos de ¿Por qué la ficción? La alta probabilidad de que las imitaciones difuminen las fronteras entre la realidad y la representación mimética de la realidad, generando un extravío con respecto al conocimiento y a la verdad, por un lado, y la eventualidad de que la poesía pervierta la moral de los individuos, por el otro, serían los dos argumentos en la base de esta aversión.

La defensa de la mímesis la inicia el propio Aristóteles, quien en la Poética establece las diferencias entre la poesía y la historia, inscribiendo la poesía en el orden de lo posible y lo verosímil, frente al orden de lo factual y lo verdadero que asignó a la historia. Desde un enfoque pragmático, Schaeffer repite el gesto aristotélico a favor de la mímesis, aunque utiliza otros criterios para demarcar los límites entre la realidad y la ficción. Al mismo tiempo, emprende la defensa de las posibilidades cognoscitivas de la ficción y la reivindica eliminándole la etiqueta de "ilusión engañosa" o "mentira”. En orden de demarcar dichos límites, define la ficción como un "fingimiento lúdico compartido" (2002:128), lo que implica un “acuerdo intersubjetivo” (129) entre emisor y receptor: por parte de uno, la intención lúdica explícita y pública; por parte del otro, la aceptación del juego y de sus reglas. En caso contrario, la actividad mimética se transformaría en un "fingimiento serio", lo que equivale simple y llanamente a la ilusión engañosa o a la mentira. Para 


\section{Lucero de Vivanco Roca Rey}

lograr este acuerdo, Schaeffer decreta "la regla constituyente fundamental de toda ficción: la instauración de un marco pragmático adecuado a la inmersión ficcional” (2002:128). No hay cómo diferenciar, según él, la representación ficcional de la referencial en cuanto a sus contenidos representacionales, porque cada una de éstas se establece según un campo de referencia determinado; equivale a decir que no es posible distinguirlas desde una perspectiva semántica. Instaurado el marco pragmático adecuado, la diferencia entre un tipo de representación y otra se instituye gracias a que el fingimiento lúdico induce a la inmersión ficcional salvaguardando la conciencia reflexiva con respecto a dicha inmersión: "La función del fingimiento lúdico es crear un universo imaginario y empujar al receptor a sumergirse en ese universo, no inducirle a creer que ese universo imaginario es un universo real" (Schaeffer, 2002:138). El acuerdo pragmático que la ficción exige supone, entonces, un marco de conciencia racional como condición necesaria para la inmersión ficcional.

Mantener la conciencia sobre la inmersión, sobre el "como si" implicado en el fingimiento lúdico compartido, forja la clave para valorar la mímesis como instancia de conocimiento y, fundamentalmente, para establecer la función de la ficción. El modo del "como si” de las artes miméticas despliega la capacidad para marcar y percibir tanto la semejanza como, también, la diferencia entre el objeto imitado y el producto de la imitación, entre la realidad y la ficción. Percibir la semejanza, por un lado, permite a Schaeffer legitimar los procesos cognitivos que operan por imitación y se interiorizan por inmersión (2002:100). Según Schaeffer, el reconocimiento de similitudes es un requisito crucial en los procesos de aprendizaje, es lo que permite construir "un modelo fundado en una parrilla selectiva de similitudes entre imitación y cosa imitada" (2002:73) por lo que "la construcción de una imitación es siempre una forma de conocer la cosa imitada” (2002:72). Por otro lado, percibir la diferencia expresa una competencia ficcional universal, una capacidad de distanciamiento que todos los seres humanos poseen para distinguir la realidad de la simulación. Con el reconocimiento de esta competencia, Schaeffer anexa a su régimen el fundamento antropológico en donde anclar la función de la ficción, a la que considera y llama "función trascendental" que reside en la posibilidad que tenemos todas las personas de reorganizar "los afectos imaginarios en un terreno lúdico, su escenificación, lo que nos da la posibilidad de experimentarlos sin que nos agobien. El efecto de esta reelaboración ficcional... es el de... una desidentificación parcial” (2002:309). Es decir, la ficción propicia —según Schaeffer - un tipo de desdoblamiento del yo que nos separa de nuestras propias representaciones, levantando una plataforma para el ensayo y el error. La expresión y experimentación de nuestros afectos, nuestras percepciones y nuestros 
recuerdos pueden tomar vida en la ficción de manera mucho más mesurada e inocua de lo que lo harían en la vida real, hasta el punto de permitirnos la fruición estética.

El diseño de ficción defendido por Schaeffer está fundado en una serie de supuestos con los que lo imaginario entra en contradicción. Si, como se ha visto, lo imaginario está en la base de toda manifestación cultural y social, no se sostiene ni se justifica la diferenciación que intenta hacer Schaeffer entre "universo imaginario" y "universo real”, ya que es la imaginación creadora - y no la reproductora - la que inventa tanto la ficción como la realidad. Es decir, es la misma operación imaginativa la que está en el origen de ambas. El "universo real” es también resultado de los sueños, las significaciones simbólicas, los mitos, las imágenes, etc. Pero parece más contradictorio aún intentar hacer depender la inmersión ficcional de un marco de racionalidad. Esto significa volver a situar a la razón en un lugar jerárquico de predominio y control sobre las formas de la imaginación, cosa que Ernst Cassirer - entre otros- en su momento refutó, incorporando la imaginación y las formas simbólicas al paradigma filosófico. ${ }^{3}$ Adicionalmente, el marco racional que actúa como condición de la inmersión ficcional no necesariamente refleja las prácticas culturales de la ficción. Justamente, Durand y Castoriadis han explicado cómo no siempre es posible conservar la conciencia sobre los sustratos imaginarios que modelan nuestras formas sociales y culturales. Por otro lado, la perspectiva pragmática de Schaeffer, que constriñe los contenidos semánticos de la ficción a un marco referencial determinado, dificulta la posibilidad de establecer referencias que transversalicen los marcos, sin riesgo de romper con las convenciones de la lectura. Esto limitaría, por ejemplo, la valorización de representaciones arquetípicas que, por definición, sobrepasan todo marco convencional. Ahora bien, es innegable que los límites establecidos por estos marcos son saludables en el sentido de no exigir a la ficción aquello que no le corresponde (equivalencia fáctica con la no-ficción, referencialidad lógica causal). Sin embargo, limitar la referencialidad de la ficción a

\footnotetext{
${ }^{3}$ Después de Kant y de lo que él mismo llamó su "giro copernicano", la subjetividad conquista un rol en la aprehensión, constitución y representación del mundo, abriendo una puerta para que otras vías no vinculantes a la razón se admitan como instrumentos de objetivación dentro de la reflexión filosófica. Una serie de propuestas teóricas se dieron a conocer en esta línea entre la década del 30 y la del 60, las que reaccionaron frente al excesivo intelectualismo sostenido hasta el siglo XIX, y a las que Durand llama "hermenéuticas instaurativas" de lo imaginario (La imaginación 68-92). Entre los intelectuales que contribuyeron a construir este prisma de subjetividad se encuentran Henri Bergson. Las dos fuentes de la moral y la religión. Buenos Aires: Sudamericana, 1962; Gaston Bachelard. La poética de la ensoñación. México: FCE, 2004; Carl Jung. Arquetipos e inconsciente colectivo. Barcelona: Paidós, 2004; Mircea Eliade. El mito del eterno retorno. Madrid: Alianza, 2003; Ernst Cassirer. Filosofía de las formas simbólicas. México: FCE, 2003.
} 


\section{Lucero de Vivanco Roca Rey}

un marco cerrado resulta demasiado empobrecedor cuando se quiere entender la ficción literaria en relación con campo imaginario, esto es, en toda su amplitud para la comprensión del sentido de las experiencias universalizables y no sólo para emitir un juicio sobre ellas o para construir una explicación objetiva. Finalmente, la concepción mimética del arte y de la literatura adoptada por Schaeffer parte de la base de que sólo existe un único mundo real - el mundo en que vivimos, el que podemos ver y experimentar- que, por lo tanto, se constituye como el fundamento y punto de referencia de toda creación artística. Según esto, la operación imaginativa propia de las actividades miméticas de la ficción sería a fin a la que Castoriadis llamó imaginación segunda (ver nota 2) la misma que el paradigma metafísico entendió como meramente reproductora y desdeñó, por más de veinte siglos, por no ser conducente al conocimiento. Desde el punto de vista de lo imaginario habría que entender lo contrario: es la imaginación creadora o primera el fundamento de todo lo existente, la que está en la base del mundo que día a día construimos.

Pero no siempre se acepta la perspectiva monádica de un mundo imitable y representable. Nelson Goodman se posiciona, en más de un sentido, en un lugar opuesto al de Schaeffer. Desde un enfoque semántico y constructivista, Goodman adopta, más bien, la idea de que existen múltiples mundos reales que se erigen como "versiones de mundos" (1990:131) sin jerarquía entre ellos, lo que puesto en términos literarios (y filosóficos) nos ubica en el ámbito de los "mundos posibles". Asimismo, frente a la concepción más pulcra de Schaeffer que se encarga de limpiar la noción de mímesis de sus efectos de arrastre, Goodman sostiene las influencias recíprocas entre los distintos tipos de mundos: "Es obvio — dice- que los trabajos de ficción literaria y los trabajos correspondientes en otras artes juegan un papel sobresaliente en la construcción de mundos, y los mundos que habitamos no son en menor medida herencia del trabajo de novelistas, autores de teatro o pintores que el resultado de las ciencias, las biografías o la historia" (1990:142). Esta demarcación implica que los mundos, tal como Goodman los asume, no provienen de la nada, sino que están hechos teniendo como modelo otros mundos previamente existentes, por lo que la construcción de cada uno de ellos incorpora siempre el anterior. Un mundo posible "parte siempre de mundos preexistentes de manera que hacer es, así, rehacer” (1990:24); según Goodman, las maneras de hacer mundos, de acuerdo a este autor, son múltiples y variadas. Debido justamente a la diversidad en su hechura y en sus resultados, la valoración de la composición y de las fronteras de cada uno de ellos no puede ser dada por un criterio único de verdad, sino - $-\mathrm{y}$ en esto sí coincide con Schaeffer - en relación a su propio marco referencial. Su validez tiene que ver con un "ajuste a aquello a lo que de una manera u otra se 
refiere” (1990:185) y su verdad con aquello que podemos rehacer y construir más que encontrar. Efectivamente - y en coincidencia con lo imaginario- ya en el siglo veinte se hicieron distintas propuestas que liberaron a la noción de mundo de sus obligaciones objetivas y racionales, dándole, más bien, fundamentos y criterios plurales para su establecimiento. De acuerdo a lo anterior, el conocimiento al que postula la literatura a partir de los mundos posibles es el que transita por construcciones reconocibles de la experiencia, o, como diría Goodman, re-cognoscibles (1990:144). Ahora bien, no obstante la modelización y la "re-cognoscibilidad", al tratarse de construcciones, estos mundos han logrado emanciparse de la dependencia mimética con respecto a la realidad y, por lo tanto, de una función únicamente reproductora. En este sentido, Goodman reivindica para los mundos así concebidos y emancipados, especialmente para los del arte y la cultura, una función que no opera "menos en serio que las ciencias en tanto forma de descubrimiento, de creación y de ampliación del conocer”. Por el contrario, afirma, la ficción nos abre a un "sentido más amplio de promoción del entendimiento humano" (1990:141).

En términos generales, el diseño de Goodman es más sintónico con el campo de lo imaginario, fundamentalmente, porque ambos enfoques se adscriben a una perspectiva semántica de la ficción. No obstante, habría que hacer un contrapunto a las ideas de Goodman consignadas aquí. Específicamente, a la reciprocidad de influencias entre los distintos tipos de mundos no jerarquizados que él defiende, admitiendo que la ficción puede incidir en el mundo real con la introducción de nuevos mundos re-hechos a partir de mundos ya existentes. El énfasis en la modelización que este operativo supone es lo que contradice el campo teórico de lo imaginario. Trascender el mundo en su facticidad — crear mundos a partir de imaginarios - es una operación propiciada por la imaginación creadora que no tiene por qué limitarse a lo previamente existente. Por el contrario, la imaginación creadora es lo previamente existente, es lo que escapa a toda determinación y, como tal, es el sustrato de lo creado e instituido y garante de nuevas creaciones e instituciones. Por otro lado, que los mundos no estén jerarquizados, según Goodman, contradice la alternancia efectiva de constelaciones imaginarias según los distintos contextos históricos, alternancia que está ligada a condicionamientos sociales e ideológicos. Y si esto es así es, porque, justamente, sí se establecen jerarquías entre los mundos más allá de nuestra intención o de nuestra decisión.

La propuesta de Thomas Pavel representa, en cierta forma, una integración de las dos perspectivas anteriores. Por un lado, desde un enfoque semántico, Pavel reconoce la existencia de dos niveles de mundos, el de la ficción y la no-ficción, aunque advierte sobre "la movilidad y la poca determinación” de sus fronteras (1995:105). Por otro lado, desde un enfoque pragmático, Pavel postula que no son los criterios ontológicos los pertinentes 


\section{Lucero de Vivanco Roca Rey}

para demarcar estas fronteras, sino, más bien, culturales e históricos, dado que "la ficción, en la mayoría de los casos, (es) una propiedad históricamente variable" (1995:101). Debido a esto, en vez de instalar el texto de ficción en un marco referencial, como Schaeffer y Goodman, Pavel establece un marco convencional (1997:175) para su validación y contextualización, ponderando, por encima de cualquier demarcación técnica y severamente rígida, las prácticas y los usos culturales de la ficción. En este sentido, la propuesta de Pavel no sólo representa una síntesis de las otras dos, sino que se organiza con un grado aún mayor de sintonía con respecto al campo teórico de lo imaginario. Aún más, Pavel se refiere a la estructura binaria que sostiene la división entre los dominios de la ficción y la no-ficción como un producto cultural, a la que Durand únicamente tendría que recordarle su irrenunciable condición imaginaria: "Quiero proponer que la estructura ontológica en dos niveles es un rasgo general de la cultura humana... Uno de ellos es percibido en tanto que dominio de la realidad inmediata, mientras que el otro nivel, que proporciona las claves de las proyecciones míticas o ficticias, sólo es accesible por mediación cultural: leyendas, tradiciones, textos, representaciones, obras de arte" (1997:175).

Según lo expuesto por Pavel, la permeabilidad de las fronteras entre la realidad y la ficción promueve no sólo la convivencia sino, también, la transferencia semántica entre ambos niveles. En este sentido, el marco convencional coincide en gran medida con las teorías de lo imaginario, al establecerse como un conjunto de criterios y de mecanismos que, en un determinado momento histórico y cultural, regulan el flujo referencial desde un dominio al otro. De esta manera, mientras que acontecimientos históricos quedan en la memoria colectiva convertidos en leyenda o relatos míticos se convierten en ficción, los elementos ficcionales influyen seriamente en la vida real, pero sin que ninguno de estos nuevos productos del intercambio se anquilosen o se osifiquen en el tiempo. Explica Pavel que "las sociedades tienden a desarrollar espacios característicos imaginarios que dan forma tanto a la vida social como a la producción cultural... por otra parte, la ficción literaria contribuye en el desarrollo de lo imaginario, ya sea otorgándole una poderosa confirmación o bien ayudando en su transformación gradual” (1995: 121-122).

Adicionalmente, la propuesta de Pavel integra una concepción funcionalista de la ficción (1995:173-180) sustentada, principalmente, en su empresa referencial y dentro de la flexibilidad dada por el marco convencional. El tema de la referencia en la ficción, según Pavel, descansa sobre dos principios fundamentales: el principio de distancia y el principio de pertinencia. En relación al primero, Pavel considera que el distanciamiento es la actividad teleológica por excelencia de toda operación imaginaria. Este principio 
supone la creación de una distancia simbólica y ejemplar, a través de la transferencia hacia el ámbito de la ficción de todas las posibles frustraciones, tensiones, intolerancias, etc., de la vida cotidiana, con la finalidad de que sean exorcizadas y sanadas en el proceso de exposición pública. "Pero esta cura no tiene efectos a menos que, de cierto modo, se demuestre que tiene cabida en lo existente” (1995:175), añade Pavel, para indicar la necesidad de complementar el principio de distancia con el de pertinencia. En este sentido, el tránsito entre un mundo y otro es de doble dirección y los acontecimientos de la vida real buscan reflexivamente, una vez hechos ficción, incidir "vívidamente en el mundo de quien los contempla” (1995:175). Según estos principios, el tipo de conocimiento al que la ficción tendría acceso - una vez más- dice relación con un nivel de comprensión más amplio de la experiencia vital, a partir de la incorporación de todos aquellos temas existenciales que, de manera esencial, preocupan al ser humano, tanto en su individualidad como en su sociabilidad. Se explicarían, así, tópicos recurrentes de la literatura de todos los tiempos, como "el nacimiento, el amor, la muerte, el éxito y el fracaso, la autoridad y la pérdida de autoridad, la revolución y la guerra, la producción y la distribución de los bienes, la posición social y la moralidad, lo sagrado y lo profano" (1995:178) que retornan desde la ficción al plano de la realidad concreta para hacer menos sombría y menos intolerable la vida. Tal vez lo más notable de este autor es la coincidencia con respecto a la línea imaginaria, al haber puesto los principios funcionales de distanciamiento y de pertinencia en un lugar central de la ficción, tal como Durand centró en la función eufémica de lo imaginario su sentido de trascendencia.

\section{EL SABER DE LA FICCIÓN}

Aún cabe preguntarse por el aporte que supone articular las perspectivas teóricas de la ficción y de los imaginarios. En primer lugar, se podría decir que lo imaginario ilumina de manera inusual un ámbito particular de la ficción que desde un análisis estrictamente técnico o teórico podría perderse ¿Cuál? El contrapunto realizado entre ambos campos teóricos muestra tanto divergencias como convergencias. Las primeras ya han sido explicitadas al exponer las propuestas de Schaeffer, Goodman y Pavel. En cuanto a las convergencias, las perspectivas expuestas coinciden en tres aspectos gruesos. Primero, en relación a la referencialidad, la ficción es el lugar donde instalar aquello que de alguna forma u otra perturba la experiencia vital; es el espacio para escenificar lo oculto, lo frustrante, lo inmanejable, lo inexplicable. Al respecto, se ha visto cómo Durand explicitaba lo que considera la mayor de estas perturbaciones: la angustia producida por la certidumbre sobre la 


\section{Lucero de Vivanco Roca Rey}

irreversibilidad del tiempo. Segundo, en relación a lo cognitivo, ficcionalizar estos elementos perturbadores e inexplicables proporciona un mayor grado de conocimiento sobre ellos y, por ende, sobre uno mismo y sobre el mundo. Sin embargo, la finitud del tiempo — el requerimiento inapelable de la muerte, el destierro original con respecto a la eternidad — no es un duelo al cual sea fácil acceder de manera directa: es necesaria su conversión simbólica y su saber provendrá también del ámbito simbólico o, como la ha llamado Lanceros, de la "escena imaginaria” (63). Tercero, en relación a la función, los efectos de este tipo de conocimiento no sólo permiten tener un mejor manejo de los elementos perturbadores, sino también trascender, corregir, reinventar la realidad que los origina. Esto es algo a lo que ya se ha referido Durand como la función eufémica de lo imaginario, orientada fundamentalmente hacia la angustia esencial: la muerte. La muerte (literal o metafórica) es, no sólo para Durand, el centro de lo imaginario: 4 "Bien podría apostarse que, desde el principio, se construye, se canta y se cuenta (en el doble sentido del término) contra la muerte y bajo su manto, que la muerte es el punto del que surgen, no sólo la mitología y la religión, sino la arquitectura, el relato, la música y el cómputo" (2006:65).

La ficción, así concebida, demarca un campo específico de conocimiento dentro del ámbito epistemológico y un saber que sobrepasa el que se logra por mediaciones meramente técnicas o teóricas (véase Lanceros). Un saber con el que el ser humano confabula sobre su propia situación en el mundo, sobre sus temores y sus esperanzas. Un saber que ha logrado sobrevivir a la negación milenaria proveniente del paradigma racional; que no desestima la agitación en la observación de los hechos, ni renuncia al misterio frente al dato objetivo, consiguiendo que se reconozca la impronta de lo imaginario en el quehacer del mundo. Un saber que ha logrado revitalizar la imaginación y la imagen —nociones ambas comprendidas en el concepto imaginario - como medios para condensar racionalidad y sensibilidad, lucidez y afectividad. De esta forma, el saber de los fantasmas apuesta por levantarse como un escenario para la comprensión por sobre la explicación y nos recuerda no obliterar la necesidad de mantener los ojos más abiertos hacia el campo imaginario y la visión más comprensiva hacia lo cultural y antropológico de lo que demandaría un análisis estrictamente técnico a la hora de abordar un texto de ficción.

${ }^{4}$ Véase también Henri Bergson. Las dos fuentes de la moral y la religión. Buenos Aires: Sudamericana, 1962; Edgar Morin. El paradigma perdido. Ensayo de bioantropología. Barcelona: Cairos, 2000; Wolfgang Iser. "La ficcionalización: dimensión antropológica de las ficciones literarias”, en Teorías de la ficción literaria. Comp. Antonio Garrido. Madrid: Arco/Libros, 1997:43-65. 
Por último, toda lectura literaria desde la perspectiva de lo imaginario encuentra un conocimiento sobre la realidad y sobre el contexto histórico al que hace referencia. Por lo tanto, estas páginas han sido formuladas bajo el entendimiento (y para evidenciar ese entendimiento) de que hoy en día ya no es posible disociar el saber imaginario, por un lado, de las mediaciones de las que se vale la historia como disciplina y los conocimientos que ésta proporciona, por el otro. La ficción, lejos de distanciarnos de los acontecimientos del mundo, lejos de desacreditar la "verdad" o las verdades que allí se gestan, es un lenguaje primordial con el que los seres humanos emprendemos nuestro camino hacia nuestros propios relatos y hacia la institución autónoma de nuestras sociedades. En La Poética, Aristóteles afirmaba que "el historiador y el poeta no se diferencian por decir las cosas en verso o en prosa... la diferencia está en que uno dice lo que ha sucedido, y el otro, lo que podría suceder” (158). Negaba Aristóteles a la historia su derecho de acceder a los sueños y a la poesía la autoridad para informar sobre la realidad. La historia y la realidad, por un lado, y el campo poético y subjetivo, por el otro, habían quedado en discordia o desarticulados entre sí, como si ambos no convergieran en el lenguaje simbólico. Una historia que se levanta a partir del saber de la literatura adquiere el compromiso de reconocer el dialogismo de la verdad y de los principios que construyen el mundo. Una literatura que contribuye con la construcción de la historia crea ese dialogismo y no sólo lo reconoce. La historia se engrandece, por lo tanto, con la literatura y el mundo se hace más inclusivo y más tolerante cuando la historia incluye el saber que de ahí se obtiene. El símbolo es el lugar en donde se cruza el tiempo del mito y el tiempo de la historia, ha escrito Lanceros (62). La historia no puede, por tanto, olvidar que es en el conocimiento que proviene del campo imaginario donde hay que buscar las señales con las que el recuento del tiempo amplía el sentido del tiempo que se cuenta.

Universidad Alberto Hurtado* Facultad de Filosofía y Humanidades Departamento de Lengua y Literatura Almirante Barroso 10, Santiago (Chile) lvivanco@uahurtado.cl 
Lucero de Vivanco Roca Rey

\section{BIBLIOGRAFÍA}

ARISTÓTELES. Acerca del alma. Madrid: Gredos, 2003.

------- La Poética. Trad. Valentín García Yebra. Madrid: Gredos, 1999.

CASTORIADIS, Cornelius. Los dominios del hombre. Barcelona: Gedisa, 1998.

DURAND, Gilbert. Las estructuras antropológicas del imaginario. México: F. C. E., 2004.

------- La imaginación simbólica. Buenos Aires: Amorrortu, 2000.

GARRIDO DOMÍNGUEZ, Antonio. "Teorías de la ficción literaria: los paradigmas”, en Teorías de la ficción literaria. Comp. Antonio Garrido Domínguez. Madrid: Arco/Libros (1997):11-40.

GOODMAN, Nelson. Maneras de hacer mundos. Madrid: Visor, 1990.

LANCEROS, Patxi. "Conocimiento". Diccionario de Hermenéutica. OrtizOsés, Andrés y Patxi Lanceros (Dir.). Bilbao: Universidad de Deusto (2006): 60-66.

PAVEL, Thomas. "Las fronteras de la ficción”, en Teorías de la ficción literaria. Comp. Antonio Garrido. Madrid: Arco/Libros (1997):171179.

Mundos de ficción. Caracas: Monte Ávila, 1995.

PLATÓN. La República. Buenos Aires: Eudeba, 2003.

SCHAEFFER, Jean-Marie. ¿Por qué la ficción? Madrid: Lengua de Trapo, 2002. 